\title{
GPR detection of karst and archaeological targets below the historical centre of Merida, Yucatán, Mexico
}

\author{
Luis BARBA1*, Jorge BLANCAS¹, Agustin ORTIZ¹ \& Josep LIGORRED ${ }^{2}$ \\ ${ }^{1}$ Instituto de Investigaciones Antropológicas, UNAM, Ciudad Universitaria, 04510 Mexico City, México \\ ${ }^{2}$ Ayuntamiento de Mérida, Avenida Mérida 2000, 97246 Mérida, México
}

Received March 2009; accepted June 2009

Available online September 2009

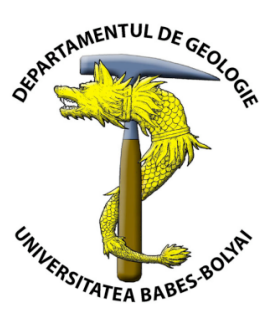

\begin{abstract}
The Historical Center of Merida has been classified as a "zone of high patrimonial value" based on the study of topography and the historical documents that show a long-term occupation, non-interrupted since preColumbian times when T'Hó was the great capital of the northern region of the Maya area. For the local government, rehabilitation of the Historical Center of Merida has been a great priority. Among others, this project includes preservation of archaeological remains (pre-Columbian or colonial) and detection of karstic zones under the city. In order to prevent damage to the patrimony, ground penetrating radar (GPR) surveys were carried out employing 200 and $400 \mathrm{MHz}$ antennas along $16.5 \mathrm{~km}$ of the city streets. After data analysis, it was possible to build a map showing the locations of subsurface karst features and archaeological remains below the street pavement, many of which correlate with archaeological platforms proposed in historic documents as well as some of the cenotes recorded in popular memory. As result, for the first time in Mexico, a local government has information available that will allow them to minimize damage to archaeological remains and mitigate risks associated with construction above shallow subsurface karstic zones within this important modern city.
\end{abstract}

Key words: georadar, karst, cenotes, Merida, México.

\section{INTRODUCTION}

The term karst describes a characteristic topography resulting from the dissolution of soluble rocks by surface or ground waters. Although commonly associated with carbonate rocks, karst processes can also act to sculpt other highly soluble rocks such as evaporites, gypsum and halite. In the case of the Yucatan Peninsula, limestone forms most of the bedrock.

Working under a joint agreement with the Departamento de Patrimonio Arqueológico y Natural del Municipio (DPANM) del Ayuntamiento de Mérida, and the Laboratorio de Prospección Arqueológica from the Instituto de Investigaciones Antropológicas (IIA) of the Universidad Nacional Autónoma de México (UNAM), an investigation of the archaeological patrimony and geology was conducted within the central portion of the city of Merida, Yucatan (Fig. 1).

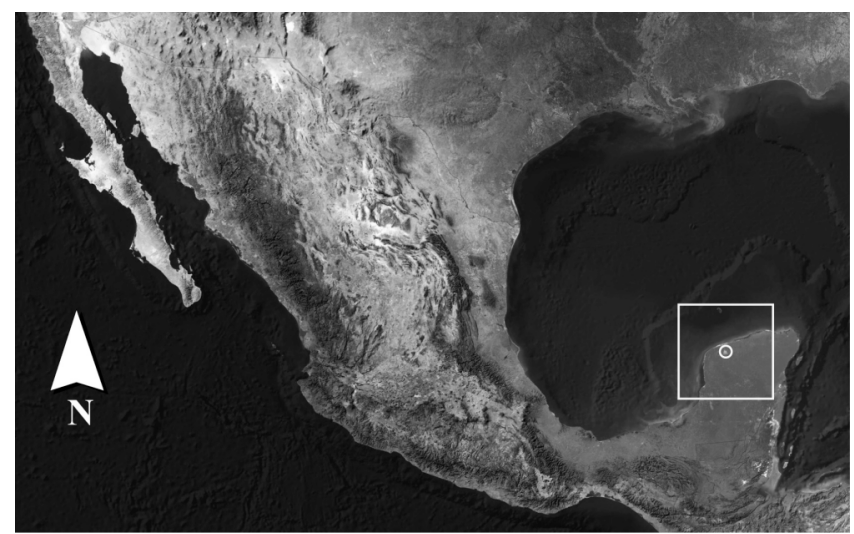

Fig. 1. Location map of Merida City.
This historical center has been classified by DPANM as a "zone of high patrimonial value" based on topographic data and historical documents. These combined data indicate continuous occupation of Merida since the pre-Colombian period, when T'Ho was the great capital of the Northern region of the Maya area (Landa, 1982; Ligorred, 2000).

A review of historical maps (Garza, 1980; Ligorred, 1998) suggest that the present Historic Downtown area of Merida was built over the remains of the ancient city of T'Hó, which appears to have been established over an elevated natural terrain lying at contour level $4 \mathrm{~m}$ a.s.1. In addition, discrete portions of higher elevations (levels 5 and $6 \mathrm{~m}$ a.s.1.) seems to be the places chosen to construct the structures that once formed the Mayan settlement known as "Noh Cah Ti Hoo" (the great town of T'Hó). Surrounding the central settlement zone, below contour level $4 \mathrm{~m}$ a.s.1., large depressions or excavated areas possibly used as building stone quarries, and later infilling sedimentary layers were also found (Fig. 2).

Integrating historical information with previous survey data yielded a map of the downtown area which included zones thought to contain the main structures of the Maya city of T'Hó. These zones were subsequently explored through a joint academic project which included GPR surveys aimed at verifying the placement of these structures and the locations of shallow subsurface karstic zones.

\section{OBJECTIVES}

The primary objective of the project was to identify possible archaeological remains preserved below the city of Merida's paved surface, with the aim of preserving 
such patrimonial resources threatened by forthcoming urban infrastructure works. The study employed ground penetrating radar surveys in order to detect: (1) karstic zones associated with caves and cenotes (sinkholes), (2) locate archaeological remains, and (3) verify the location of the sacbe remains that possibly connected T'Hó with the contemporary Mayan centers of Caucel or Xoclan.

The methodology employed in this study benefited from the use of in-situ archaeological prospection techniques, which provided constant feedback during the data acquisition phase (Barba and Ortiz, 2001). Anomalies detected could be represented in either radargrams or time/depth slice maps depending on the answers being sought. Ground verification of the GPR data was accomplished by excavating a number of test pits in order to verify the presence of some archaeological resources. The architectural remains identified were subsequently consolidated according to international standards and their building system.

The use of GPR equipment permitted the Archaeological Prospection Laboratory from the IIAUNAM to carry out an investigation of the archaeological remains buried below the modern city of Merida (Barba et al., 2008). The GPR equipment employed consisted of a GSSI SIR System 2 equipped with, 200 and $400 \mathrm{MHz}$ monostatic antennas and 100 $\mathrm{MHz}$ biestatic antennas.

All locations suggested by previous cartographic analysis, as well as possible target area identified by the previous Josep Ligorred - DPANM study were investigated.

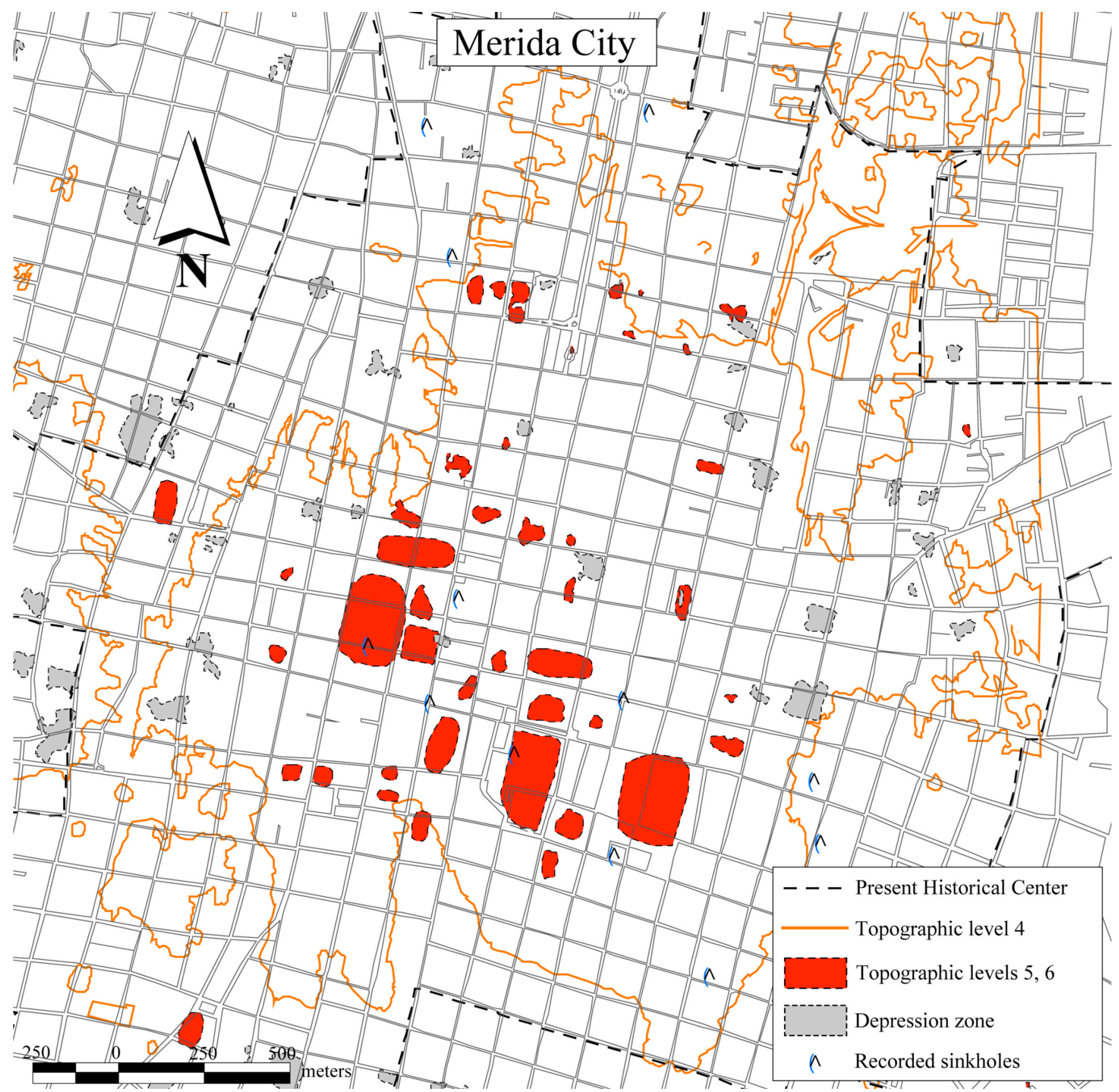

Fig. 2. Levels in Historical Center of Merida. After the photogrametric map of Merida, Yucatan. Made by Ingenieria Técnica de Estudios y Proyectos S. A. de C.V. (ITEPSA) for the Subdirección de Infraestructura Hidráulica Urbana e Industrial de la Gerencia Regional de la Comisión Nacional del Agua. May 1991. 
Over the course of two weeks, 127 GPR transects were surveyed, amounting to a total length of 16584 meters. GPR equipment settings were as follows: 32 traces per second, 80 and $160 \mathrm{~ns}$ windows, and 512 and 1024 samples per trace. The data processing phase employed GSSI Radan 6 software, in order to remove background noise, improve resolution, normalize horizontal distances, and make depth estimates.

\section{RESULTS}

The GPR survey revealed anomalous features of both natural and anthropogenic origin. In particular, a number of the anomalous features suggested the presence of buried archaeological remains while others appeared to be related to karstic zones.
Continuous horizontal reflections observed on a number of GPR profiles were interpreted to represent archaeological levelling. The locations of these anomalies showed a close correlation with higher elevation areas, as established by previous topographic studies.

In order to visualize the spatial distribution of the anomalies in relation to the existing urban plan, anomalies were plotted onto a map of the city. On the other hand, the anomalies were interpreted according to the characteristics of the reflections (shape, depth, amplitude reflection, hyperbolic diffraction), archaeological information, and test pits.

Additionally we employed common-midpoint (CMP) survey using the $100 \mathrm{MHz}$ antenna to aid in the selection of recording parameters and to provide an electromagnetic velocity profile for this site (Fig. 3).

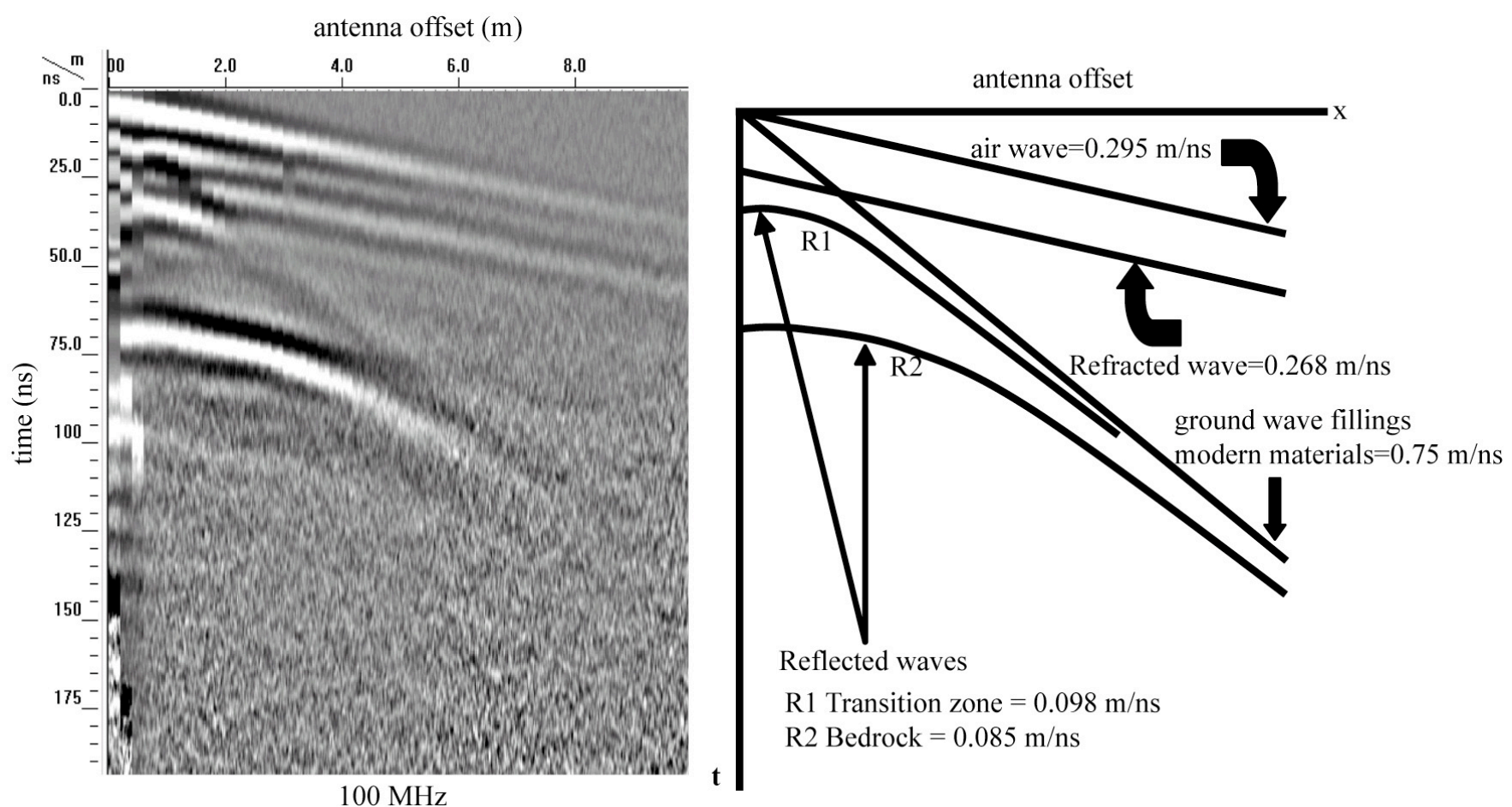

Fig. 3. CMP record with various refraction and reflection events. CMP data are useful in determining GPR acquisition parameters such as antennae separation, antenna frequency, range as well as velocity information for use in the interpretation of profile data.

It is advisable the CMP data collection during any GPR reflection study, if at all possible. Information obtained from a CMP record is invaluable in the interpretation of the data, (Blancas, 2000).

The common-midpoint (CMP) setup used in this study involved recording a GPR reflection trace with the transmitting and receiving antennae separated by 0.2 meter, then moving the antenna away from each other at 0.2 meter intervals to record additional traces. This procedure provides a set of traces with increasing offset distance.

Antenna separation values which facilitate the recording of reflections are easily determined by observing the CMP data. Velocity can be determined by analysing near surface arrival times.

The CMP study showed three main layers within subsoil:

- Pave modern materials and shallow fillings.

- Transition zone. Corresponds to a mixture of weathered limestone and clays.
- Limestone bedrock.

Line F19 surveyed buried remains present under street 67 A and consequently under the public park that exists in that location. Reflections observed in (Fig. 4a), appear to be related to the presence of small cavities and fractures within the limestone bedrock, and confirm the presence of a "cenote" (sinkhole) recorded in oral tradition. In the vicinity of the intersection with street 67 and 65 , between 100 to 310 meters, a horizontal reflection (Fig. 4b) which correlates with a high elevation area (red spot in Fig. 2) was also identified.

The GPR transect line F79 on the street 64 also recorded strong reflections in transitional zone and limestone bedrock, from 327 to 368 meters (Fig. 4c), the hyperbolic diffraction and scattering pattern may correspond with fractures and likely karstic zone or cavities.

The GPR transect identified an anomalous area of karst included in both transition zone and limestone bedrock. 

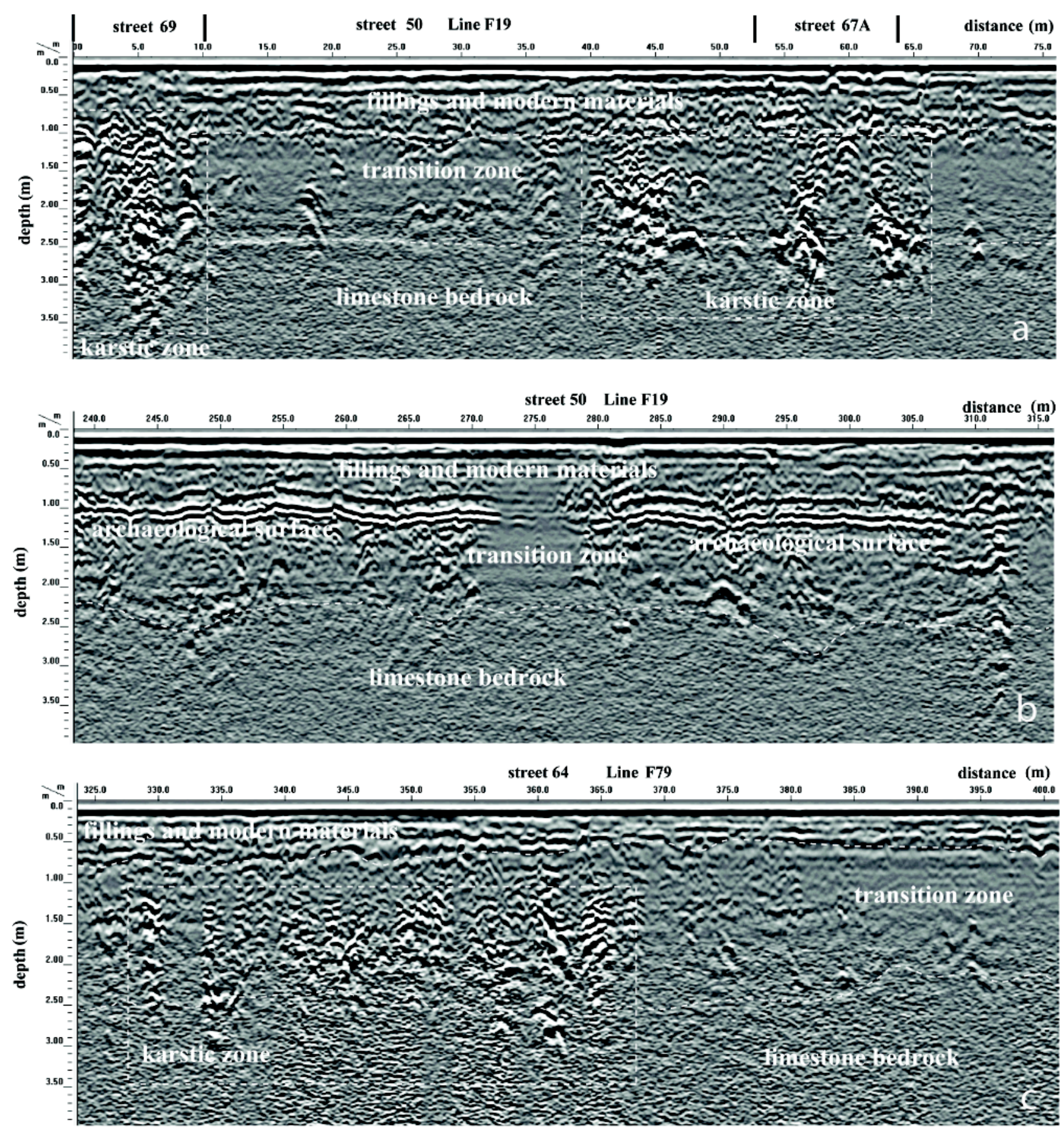

Fig. 4. Radargrams Line F19 and Line F79.

\section{CONCLUSIONS}

Most of the GPR profiles revealed a diffuse limestone bedrock contact lying at depths ranging from 1.5 to $2 \mathrm{~m}$ below the paved surface. This contact showed a slight change in the amplitude of the reflections. However, in places, shallow clayish soils overlying the limestone bedrock yielded rapid signal attenuation.

In a number of areas, anomalous reflective patterns were returned from depths below the soil-bedrock contact. These anomalies have been interpreted to represent fractures and discontinuities in the limestone bedrock, which may represent incipient karstic zones and/or the uppermost parts of subsurface cenotes.

Studia UBB, Geologia, 2009, 54 (2), 27 - 31
The proposed higher contour levels correlate with strong continuous horizontal reflections at a depth of $1 \mathrm{~m}$. In places, the GPR data revealed well-defined, shallow reflective contacts, interpreted to represent culturally levelled surfaces prepared to build the ancient Mayan structures. As a result of the joint research effort, a map of the Historical Center of Merida was compiled, which included GPR anomalies and corresponding interpretative data (Fig. 5).

These data provide new insight into the distribution of shallow archaeological resources, which will allow local city authorities to make low impact decisions concerning the planning of modern urban developments, thus successfully preventing unnecessary damages to the archaeological patrimony and reducing the risk of the development over potentially hazardous karstic zones below the city of Merida. 


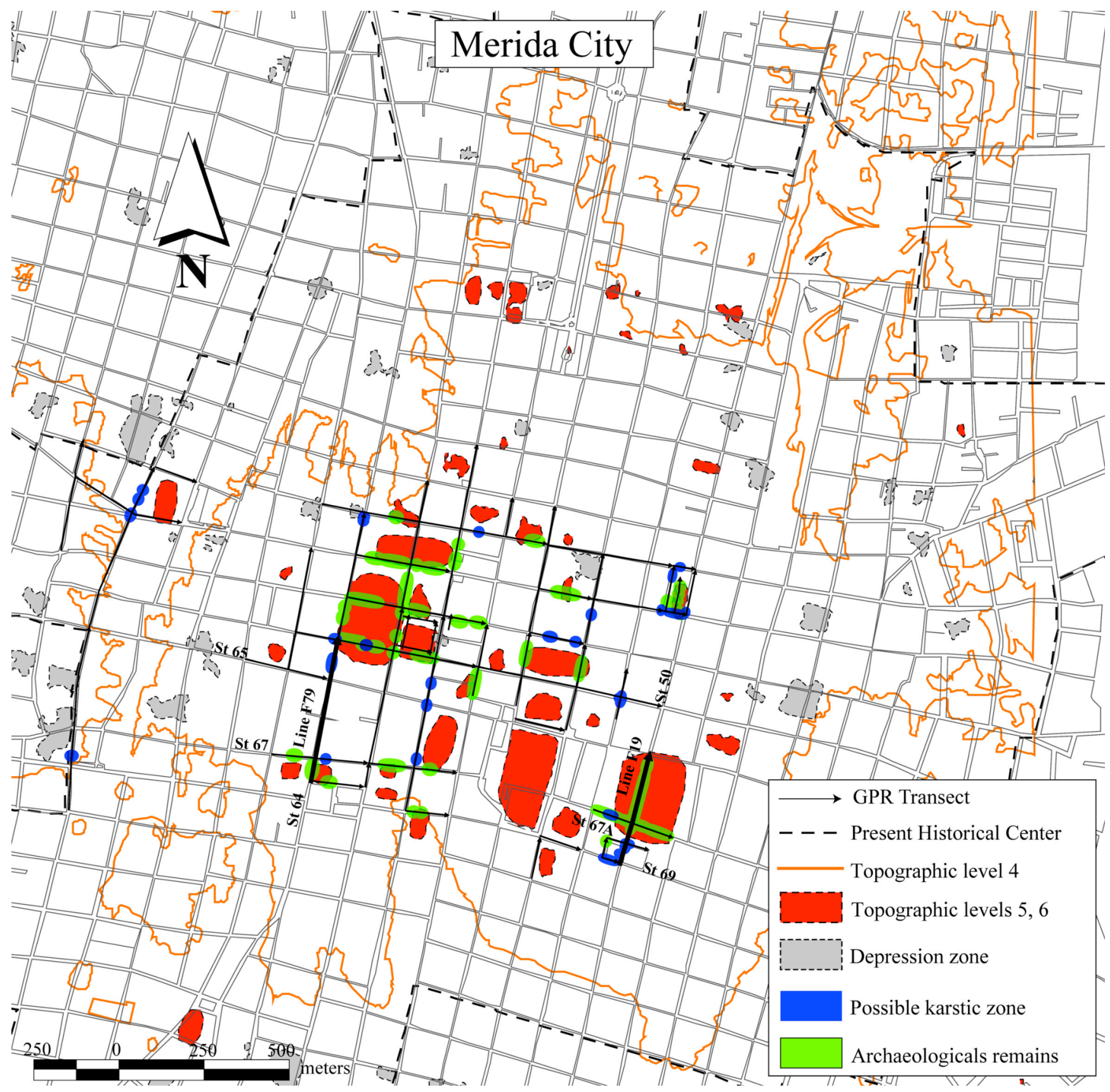

Fig. 5. Map of the Historical Center of Merida representing the distribution of the radar anomalies related with karstic zones in blue, and archaeological remains in green.

\section{R E F E R E N C E S}

Barba, L., Ortiz A. 2001, A methodological approach to the study of archaeological remains in urban contexts. Proceedings of the $32^{\text {nd }}$ International Symposium on Archaeometry. CD ROM, IIA, UNAM, México.

Barba, L., Ortiz, A., Blancas, J. \& Ligorred, J. in press, Reencuentro con T'Ho: estudio geofísico del centro histórico de Mérida. Memoria del IV Seminario Internacional de Conservación del Patrimonio (April 9-11, 2008), Merida, Yucatan.

Blancas, J. 2000, Principios y Aplicaciones del Método de Radar de Penetración Terrestre (GPR), Thesis, Facultad de Ingeniería, UNAM, México.

Garza, S., Kurjack, E. 1980, Atlas arqueológico del estado de Yucatán, INAH, Mexico.
Landa, F.D. 1982, Relación de las cosas de Yucatán. Editorial Porrúa, $12^{\text {th }}$ ed., México.

Ligorred, J. 1998, T'Hó: La Merida Ancestral, FAMSI grant inform. http://www.famsi.org/reports/96018es/index.html.

Ligorred, J. 2000, T'Hó en el Centro Histórico de Mérida. Ichcanzihó magazine, Departamento de Patrimonio Arqueológico y Ecológico, Dirección de Desarrollo Urbano, Ayuntamiento de Mérida, n. 1, July-September, 2000. 